\title{
Promotion the E-Learning Success in Universities in Baghdad Through Enhancing their Organizational Innovative Collaboration Environment: A Qualitative Study
}

\author{
Mohamed Ali Mahmod, Asma Md. Ali \\ Dept. of Information Systems, International Islamic University Malaysia, Kuala Lumpur, Malaysia \\ mmashadani@gmail.com \\ sis_asma@iium.edu.my
}

\begin{abstract}
Electronic Learning (e-learning) is the process of using the electronic educational shapes of information and courses contents in an inventive way. E-learning is the process of education that offered can be divided into online or distance education, which means that it can deliver education to everyone around the world online through the electronic means such as the internet from different distant countries. In order to promote the e-learning process universities in developing countries such as Iraq, the enhancement of the e-learning success needs to some factors that should be fit with the revolution of technology and enhance the learner's knowledge. Universities in developing countries such as Iraq, in order to be fit with the rapid growth of technology, it needs to collaborate with other national and international universities to develop e-learning tools and methods. In order to contribute to the success of the e-learning process in universities in Iraq, these universities have to adopt collaboration culture with other universities and innovative culture to follow the global innovation in e-learning process around the world. This paper developed an integrated framework of e-learning through an organizational innovative collaboration environment, analysed it qualitatively through the interviews with students, staff and elearning centres and found strong relationships between its elements which could participate to improve and add values to the e-learning process in universities in Baghdad.
\end{abstract}

Keywords— E-Learning, Collaboration, Innovation, Organizational culture, Success

\section{INTRODUCTION}

For the purpose of improving the acquiring and sharing knowledge and enhancing the performance of the education process, a lot of universities and colleges have become offering e-learning services for its students. Elearning can be considered as an efficient tool for offering rich course contents to students. In addition to that, elearning also allows instructors and students accessing the knowledge and sharing it efficiently [1]. The collaboration between universities in e-learning through joint innovative projects could add values to the e-learning process in Iraq. According to Salmons [2], collaboration as "constructing knowledge, negotiating meanings, and/or solving problems through mutual engagement of two or more participants in a coordinated effort using the Internet and electronic communications".

However, on the other hand, Open innovation (OI) is the process of cooperation and collaboration of multiple participants to give new solutions [3]. The procedures of the Open Innovation process include adapting to a culture, gathering and screening thoughts, collaborating with outsources participants and construct the strong basis of knowledge [3].
There are Avicenna centres for e-learning in some universities such as the University of Baghdad and the University of Mustansiriyah in Baghdad [4].

The strategy of e-learning in the University of Mustansiriyah located in Baghdad is contributing to making Learning Management Systems (LMS) available to enhancing ecurriculum and allow to more students to register and learn. This aim of this strategy is to improve the education process output through employing new techniques in Information and Communication Technology (ICT) facilities through collaborating with other international universities to support the teaching and learning process such as offering shared innovative e-learning services to the students.

\section{INFORMATION SYSTEMS SUCCESS MODEL OF DELONE AND MCLEAN}

Delone and McLean put an essential reference model to the improvement process of the Information Systems in 1992, and they called it "IS success model".

In 2003, Delone and McLean refreshed their model to wind up comprised of six variables which are quality of service, quality of content, quality of a system, using of a 
system, a satisfaction of the customer and net benefit. Figure 1 illustrates the updated IS success model (2003).

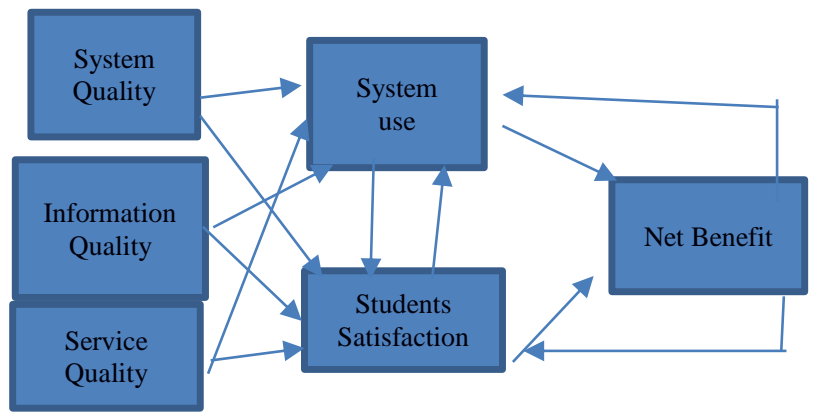

Figure1: IS success model (2003) [5]

For the purpose of forming an e-learning success model, IS success model will be used for e-learning [5]. The previous studies did not consider the individual effect of the student and also the capabilities of the developing countries which relates to the individual technological. In addition, they also did not take into their account the university impact. Increasing the ease of treatment and communication and improving the coordination could enhance the role of the organizational university impact in improving the e-learning process [6].

In order to create a collaborative e-learning environment, the cooperation and collaboration between universities could contribute to share learning events or exchanging ideas in discussions. Jakobus Smit et al [7] described in their research project the role of the organizational culture in promoting information systems management, and they consider in their model the coordination and relationships as main factors of the organizational culture.

It was found that the effects of the organizational culture on information system success, including isolation versus collaboration, centralized versus. decentralized control, internal or external focus and others. They found that collaboration-oriented culture is more feasible use with the implementation of the Information Systems. furthermore, they found that oriented internal culture and the inclination to use information from outside requires information system use and implementation [8].

\section{OPEN INNOVATION PARADIGM}

Open innovation plays an important role in adding values and enhancement to the e-learning process [9]. the collaboration among universities could help in developing new knowledge depending on the Open Innovation processes.

In order to integrate external information perfectly, the Open Innovation steps are the inevitable process which could enable organizations to achieve that. Open innovation is a modern pattern of collaborating and cooperating with the external environment of an organization. The open innovation role in e-learning can be represented by modifying or adapting current curricula at universities in cooperation with other universities and companies, considering particular collaboration and open innovation requirements [10].

Universities should develop its capabilities to ensure making use of external knowledge, ideas and resources. Universities-based research knowledge requires additional investment by businesses in building collaborative networks with external scientists and internal research expertise [11]. Friedman and Angelus [12] defined Open Innovation as "the process of managing the interaction and collaboration of multiple partners to deliver new solutions".

Open Innovation model composed of fundamental stages which are a cultural adaptation, collecting thoughts, collaborating with external parties and make a learning basis [13].

The previous studies about using IS success model in the aspect of developing of the e-learning process have concentrated on just the qualities of e-learning system, services and content and its use and user satisfaction without focusing on how to develop it and which means and resources that could be more feasible to achieve the e-learning process goals.

However, on the other hand, the previous studies about using open innovation model have focused on the industry like small and medium enterprises without concentrating on the academic field.

This paper will combine both of IS success model and open innovation model to develop the e-learning processes through benefiting from open innovation by using external ideas and resources with the internal resources together such as using external shared elearning services like MOOCs with the learning management systems (LMS) like Moodle, which could enhance the qualities of the system and contents and adding values to the quality of the offered services.

\section{OTHER FACTORS CONTRIBUTING TO THE DEVELOPED FRAMEWORK}

In our proposed framework, we classify factors to independent variables, mediating variables and dependent variables.

The independent variables can be illustrated as the following:

\section{A. Student Infrastructure Capability}


1) Computer ownership and self-efficacy: the profession level of students in using their personal computer for study and other activities [14].

2) Accessing of the Internet: this indicates to the student's ability to ensure having an internet connection and accessing the websites [15].

B. Service Quality: This refers to the support correlated with the IT units. These qualities of service should ensure accuracy, and reliability of the offered services. Personal skills, capabilities and experience should be involved in the service quality [16].

C. System Quality: to ensure the quality of the system, flexibility, reliability, availability, easiness of learning, ease of use as well usability and response rate should be available [17].

D. Information and Course Content Quality: This indicates to content, services and features offered on the website. To ensure the quality of the curricula, the information and course content must be relevant to the student, accurate and reliable [18].

E. Open Innovation: Open innovation is the is the way toward managing of the cooperation and collaboration with other partners to convey new solutions [19].

F. Shared e-learning services: This indicates to the elearning services shared among collaborated universities and institutions in the field of e-learning such as using cloud computing with learning management system (LMS) which it is considered as the most breathtaking collection of LMS [20], and Massive Open Online Courses (MOOCs).

\section{G. The organizational culture}

The organizational culture fundamental functions can be noted clearly in enhancing the sociable system in the organization, and solving problems of internal integration and external acclimation successfully [21].

However, the collaboration between universities together and between it and industries is considered one of the most important cultures of universities that could participate in enhancing universities e-learning processes. It was found that the collaboration between universities, companies and research institutes in computer science domain could add more important values of the learning process through offering new syllabuses, new curricula, and various methods of learning and teaching [22]. The collaborative e-learning is considered an inevitable need for learning organization kind. Developing a collaborative culture of knowledge sharing could play a crucial role in succeeding the e-learning process [23]. sharing ideas and resources, and constructing a general agreement among collaborated members are considered as the essential matters for the collaboration process in e-learning [24].

The collaborated Universities between each other in doing joint projects have a shared sight to promote the e-learning. Dividing into effective multiple professional teamwork could participate to perform the shared sight among the collaborated universities [25]. The e-learning process could be promoted through depending on the international collaboration between universities and industries together from different countries, which could lead toward performing joint innovative international projects in e-learning field. This study will focus on benefiting from using collaborative and adhocracy (innovative) cultures among universities together and between it and industries as will research the organizational culture influence on the net achievements of electronic learning.

And the dependent variables which we put it under "net Achievements" variable composed of System Use, User Satisfaction, and Net benefit can be defined as the following:

A- System use: This indicates to the method and trend of using the system by students [26].

B- Student satisfaction: This refers to which student is satisfied with the system and its offered services and whether this e-learning system caters student's needs.

c- Net benefits: This indicates to the extent to which elearning system contributes to improving student knowledge, improved productivity, cost reduction and save time [27], making external and internal mutual projects and benefiting from new ideas and resolving e-learning-related issues. might ensure continuous enhancement for the e-learning system and the entire e-learning process.

This study will use a combination of IS success model and $\mathrm{Ol}$ model together in order to identify the most feasible elements which could participate to enhance and adding values to the e-learning systems in public Iraqi universities.

Therefore, this study determined some gaps in literature review such as poor previous research on the elearning success, lack of concentration given to the participating elements of e-learning process using the IS success factors, the benefiting from the Open Innovation process in e-learning, and the lack of focus on the importance of the individual learner's elements, organizational (university) impact and culture in succeeding of e-learning. This study seeks to address these gaps. Figure 2 illustrated the integrated developed framework of this paper. 


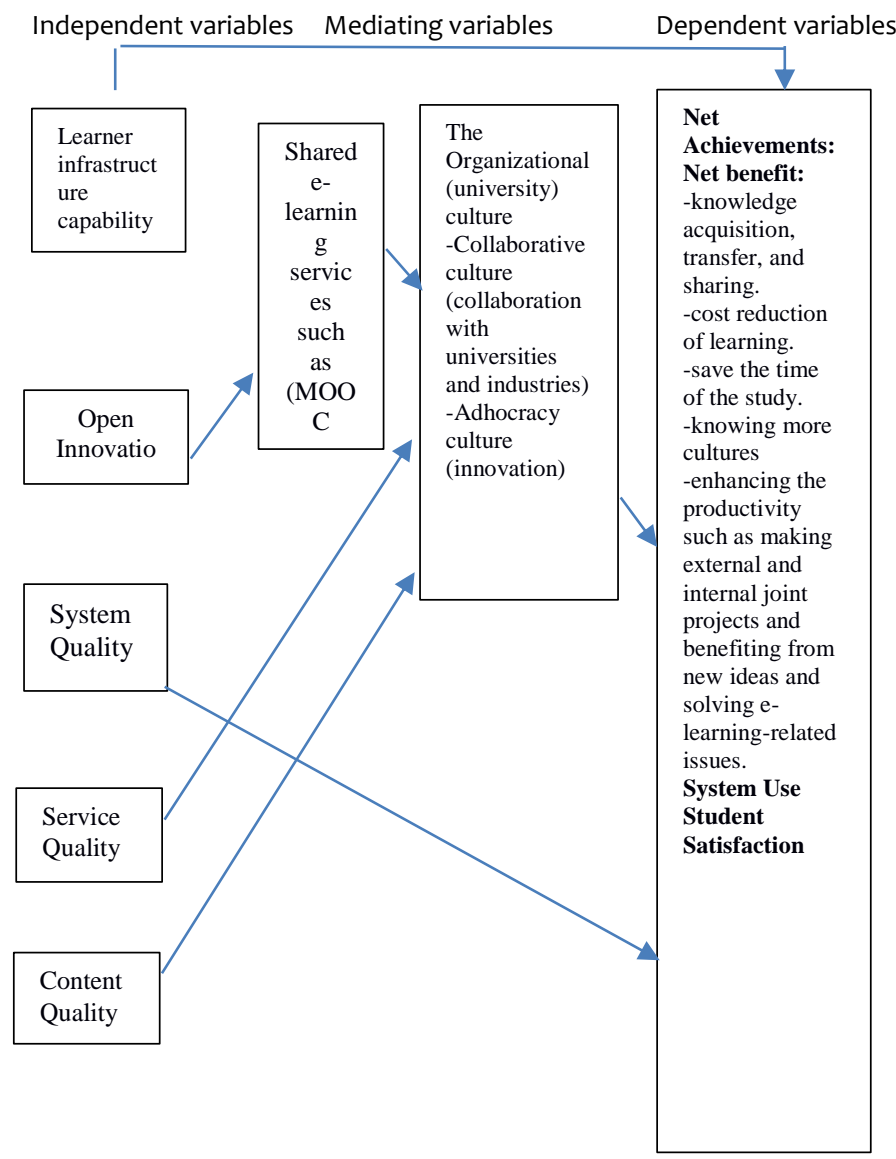

Figure 2: The developed research framework

\section{METHOD}

A structured one-to-one interview was conducted with a list of questions that address the topic and findings of the quantitative research, making this study an explanatory mixed methods design. Respondents were allowed to further expatiate on the topic and findings, later giver their personal opinion.

The interview which involved 11 participants, 5 of which are postgraduate students, 4 academic staff and 2 directors of Avicena e-learning centres, also took around 10 minutes and were conducted after the analysis of the quantitative data. Based on the interview protocol, the topic and the interview questions were giving to them, the time, date and place of the interview was written, the name of the interviewee was pen down, and explanation of the purpose of the study was made, confidentiality and length of the interview were recorded using a mobile phone recorder, analysed and a formal coding of each of the responses were conducted by the researcher.

A qualitative study is conducted purposely to complete findings which provide rich explanations to an earlier quantitative research as "completeness" [28]. The idea if an interview is not for generalization but to get a comprehensive understanding of few people [29]. As for this study, the aim is to get more explanation regarding some variables, hypotheses and the result of analysis obtained from the survey. Researchers are employed to group data into sections that will be considered as "theme" [30]. Some researchers suggested that analysis should be made in order to get a detailed and systematic recording of the theme and issues addressed [31].

Therefore, the analysis is grouped into their experience and use of computer and internet, and the ability to generate electricity for a period long enough for studies, the motivation for enrolling for e-learning, and the relationship between the contributing IS success factors (service quality and information and content quality), leaner infrastructure capability and the net achievements. It also seeks the relationship between the system quality and the organizational university cultures, and the relationship between open innovation through MOOCs and through the organizational university culture and Net achievements. And lastly, seek their opinion on the success of e-learning and how it is considered successful and suggestion for improvement.

The second phase of the interview seeks to address the result of the analysis by getting a direct opinion from the experts. This phase involved the learner infrastructure capability which was found to relate directly to the net achievements of the e-learning process. And system quality influence on the net achievements which composed of net benefits, system use, and user satisfaction. In addition, these interviews seek to address the expected impact of the service quality and content quality on the organizational university collaborative and innovative culture.

Furthermore, the interviews seek the effect of using open innovation on the MOOCs and the effect of MOOCs on the organizational university culture and then the influence of the organizational university culture on the net achievements.

\section{ANALYSIS}

All interviews with the students supported that the system quality, service quality and information and content quality is so beneficial to the students. Interview C (student) commented saying:

'the quality of e-learning system and offered services and ecourses play a crucial role in determining learner's desire whether to continue in this study or not because it is important to be free of strops, delays, sophisticated browsing' (student).

Furthermore, the interviews with postgraduate students have indicated to the main factors that motivate them to study online can be summarized as the quality of 
the e-learning system and it's being fast responsive with no delays.

However, on the other hand, most interviewees have indicated to the importance of the collaboration between universities and industries in offering e-learning content practical courses where one of the interviewees commented:

'the collaboration between universities and industries is very important for student's outcomes because it relates the theoretical and practical aspects together. Regarding our university achievements in this field that we have made an agreement with Cisco academy for networks in which this academy present online theoretical lectures and practical laboratory training and application via the internet. I think that this type of collaboration between our university and cisco academy will enhance the e-learning process through benefiting from the external practical experience of cisco together with the theoretical material and CISCO MOOC and then will improve student's outcomes. This is a simple example of our achievement in this field' (Academic staff F). While regarding the innovative culture of universities, all the respondents indicated to the crucial role of the innovative culture of universities through encouraging elearning teams and students together to contribute to innovate and invent new means and tools and benefit from new technologies to develop e-learning. So, the innovative culture will contribute heavily to developing e-learning and succeeding it whether internally or externally or together through open innovation.

Moving to the potential importance of the MOOCs in supporting the e-learning process in universities in Baghdad, most of the respondents have expected that the Iraqi universities could benefit from MOOCS, one of the interviewees indicated to the importance of benefiting from MOOCs in supporting the e-learning in universities in Baghdad by commenting

'we can benefit from American, Germany, Japanese, Malaysian knowledge and experience in MOOCs through acquiring it and developing our curricula and practical labs and making it as suitable with the advancement of technology in the world. In addition to that, students can save time and money while following his e-learning study through MOOCs' (Avicena centre of e-learning staff K).

However, on the other hand, all interviewees supported the proposition that Learner Infrastructure Capability (LIC) which comprises computer self-efficacy skills, internet access and electricity generation has the crucial role in promoting the e-learning process and enhancing all its factors through its contributing in knowledge acquisition and sharing via internet and reducing cost of the learning, and other distinctive roles in promoting the e-learning process.
The positive impact can be noticed through fitting the learners' computer skills with the existing e-learning system and their ability to access the internet from their universities and/or homes.

All the interviewees indicated that the importance of LIC and its contributing role in the success of e-learning and its significant influence on the Net Achievements composed of net benefits through knowledge acquisition, transfer and sharing, cost reduction of learning. save the time of the study, cross culture, improved productivity (innovative joint projects and new ideas and solving elearning-associated problems, system use and user satisfaction.

Question 1: Using external e-learning resources with internal resources through benefiting from using shared e-learning services such as Massive Open Online Courses (MOOC) platforms through the collaboration with other international universities and industries, it was found that it has high significant will enhance the e-learning process in your university, what are reasons behind that?

The answers of interviews prove the significant impacts of using and benefiting these universities from external resources of e-learning through sharing e-learning services depending on following a collaborative and adhocracy/innovative culture towards developing the elearning process in universities in Baghdad where interviewee J (Avicena center of e-learning) stated that: 'we can benefit from external e-learning resources and share contents and develop new curricula through sharing MOOC, for example, we can benefit from using Jordanian MOOC and Malaysia MOOC through the collaboration with Jordanian and Malaysian universities. Sharing contents could help us to develop new curricula and could help students to acquire knowledge and share it and help them to save time and reduce the tuition required fees' (Avicena cener of e-learning staff J).

'we expect that the collaboration between University of Baghdad and University of Huddersfield from UK in exchanging the experts and develop the scientific curricula and e-learning will contribute to benefit from the UK experience in developing e-learning through sharing their experience in this field' (Academic staff $H$ ).

Question 2: It was found that E-learning system quality has a positive significant impact to promote the net achievements of e-learning through the innovative and collaborative culture of the university with other international universities and industries. However, in fact, these mentioned factors theoretically have high positive significant on the Net achievements of e-learning. What do you think about that?

The replies of most interviewees supported that System Quality has an important role in succeeding e-learning 
through being of system as responding quickly and its ability to offer flexible and updated course content and whether the system is easy to use system, no delay, easy and clear navigating, unwanted quitting and other problems. So, the system quality, service quality and content quality will contribute heavily to developing elearning and succeeding it through our innovation, inventions and collaboration with others.

Question 3: It was found that E-learning service quality and content quality have a positive significant impact on the organizational university collaborative and innovative cultures of the university with other international universities and industries. However, in fact, these mentioned factors theoretically have high positive significant on the organizational university culture. What do you think about that?

The replies of the interviewees indicated that the elearning content quality and service quality influence positively on the organizational university collaborative and innovative cultures. Some of the respondents indicated to the role of the content and service qualities in succeeding the collaboration and innovation processes among universities in enhancing the e-learning process through extending shared contents and curriculum and joint elearning services which might ensure that the contents are available, accurate, updated, well organized, useful and its completeness due to the experience of the joint academic staff. In addition to that, the collaboration and innovation cultures of universities might motivate IT personnel of all collaborated universities due to their commitments with all collaborated universities to be always available, knowledgeable, active and to add value to the e-learning process through ensuring that all the services are important and through their following the offered services, adding new tools and benefiting from new rapid technologies. On the other hand, the quality of contents is very important, for example, the content quality depends on our collaborate with MIT university and then we can benefit from their online courses which could add value to the e-learning process through improving our learning management system Moodle through adding other tools, means and services such as using cloud computing technique and benefiting from their edX MOOC.

Question 4: It was found that the university culture has a positive significant impact on the net achievements of the e-learning process. However, in fact, these mentioned factors theoretically have high positive significant on the net achievements of the e-learning process. What do you think about that?

The replies of the interviewees indicated that the elearning organizational university collaborative and innovative cultures affect positively on the net achievements of the e-learning process through enhancing the knowledge acquisition process through sharing curriculum, joint lectures, various e-learning resources. In addition, the collaboration between universities could improve the learning management systems of the university through enhancing it with other tools and technologies such as MOOCs, and facilitate sharing contents, resources and others and adding more extended storage such as using cloud computing tools. Furthermore, the collaboration process could help students to reduce the cost of studying and saving the time of study and help the university to reduce the cost of the development process in e-learning. Also, this type of collaboration could lead to making the learners more recognized with other cultures from different countries.

The results of the qualitative method showed that there is a significant relationship between the student infrastructure capability and the net achievements, and system quality is also found to have a positive significant influence on the net achievements. Furthermore, the analysed interviews data supports the importance of service quality, information and content quality on the organizational university culture. Lastly, the interviews showed that there is a positive strong relationship between the organizational collaborative and innovative cultures on the net achievements composed of net benefit, system use and user satisfaction.

\section{VII.CONCLUSIONS}

This paper determined the main factors which could contribute to e-learning success in universities in Iraq. In addition to that, this paper proposed an integrated framework for e-learning which links the individual impact with the organizational impact The proposed framework consists of hybrid models of both IS success model and open innovation model. The integrated proposed framework depends essentially on an innovative and collaborative environment due to the policy and strategic goals of the ministry of higher education and scientific research in Iraq. The interview data confirm and explain the research model presented by this study. This paper shows a newly developed construct in the field of information systems which the study refers to as learner infrastructure capability and the organizational university innovative and collaborative culture.

\section{REFERENCES}

[1] Haythornthwaite and Andrews, "Elearning theory and practice". Sage publications Inc: London, 2011.

[2] Salmons, "Taxonomy of Collaborative E-Learning", PP.2, 2006.

[3] M. Roshani, M. Roshani, N. Lehoux, and J. Frayret, "University Industry Collaborations and Open Innovations: An Integrated Methodology for Mutually Beneficial Relationships UniversityIndustry Collaborations and Open Innovations: An Integrated Methodology for Mutually Beneficial Relationships," no. June 2015. 
[4] Ministry of Higher education and Scientific research in Iraq, 2015.

[5] S. Petter, W. DeLone, and E. McLean, "Measuring information systems success: models, dimensions, measures, and interrelationships," Eur. J. Inf. Syst., vol. 17, no. 3, pp. 236-263, 2008.

[6] A. Kamel, D. Lakhder, and Z. Ammar, British Journal of Arts and Social Sciences, ISSN: 2046-9578, Vol.9, No. 2, 2012.

[7] S. Jakobus; Dellemijn, Marielle; and Silvius, Gilbert, "The Relationship Between Organizational Culture, Information Systems, Management and Change Readiness". PACIS, pp. 143, 2012

[8] S. Wang, N. Archer, Y. Pei, "In IFJP International Federation for In Coronation Processing". Volume 254, Research and Practical Issues of Enterprise Information Systems II Volume I. cds. L Xu. Tjoa A. Chaudhry S. (Boston: Springer). pp. 617-626, 2007.

[9] B. Kux, "Universities and Open Innovation: a new research paradigm”,2008.

[10] EURIS, "Embracing OPEN INNOVATION IN EUROPE: A Best Practices Guide on Open Innovation Policies euris project”, 2012.

[11] K. R. Fabrizio, "The use of university research in firm innovation", Chesbrough, H.W., Vanhverbeke, W. and West, J. (Eds), Open Innovation: Researching a New Paradigm, Oxford University Press, Oxford, pp. 134-61, 2006.

[12] M. Freeman and E. T. Al, "The impact of individual philosophies of teamwork on multi-professional practice and the implications for education," 2000.

[13] S. Wang, "From e-learning to Mooc", vol. 9, pp. 35-42, 2014.

[14] J. Burns, "A third of poorest pupils without internet at home", BBC new education and family, 2013.

[15] J. A. Van DIJK, "The evolution of the digital divide the digital divide turns to inequality of skills and usage", 2012.

[16] V. Ndume, F. N. Tilya, and H. Twaakyondo, "Challenges of adaptive e-learning at higher learning institutions: a case study in Tanzania", International Journal of Computing and ICT Research, vol. 2, no. 1, 47-59, 2008.

[17] A. Leclercq, "The perceptual evaluation of information systems using the construct of user satisfaction: case study of a large French group". The DATABASE for advances in information systems, vol. 38, no. 2, pp. 27-60, 2007.

[18] R. D. Freeze, K. A. Alshare, P. L. Lane, and H. J. Wen, "IS success model in e-learning context based on student's perceptions", Journal of Information Systems education, vol. 21, no. 2, pp. 173-184, 2010.
[19] D. Rossin, K. R. Young, D. K. Barbara, and M. G. Yi, "The effects of flow on learning outcomes in an online information management course", Journal of Information Systems Education, vol. 20, no. 1, pp. 87-98, 2008.

[20] M. Friedman, H. Angelous, "Best Practices in Collaborative Innovation How Manufacturers and Retailers Can.", 2009.

[21] R. Ismail, "Organizational Culture Impact on Information Computer Science and Software Techniques in 2011 Organizational Culture Impact on Information Systems Success," no. APRIL 2011, 2016.

[22] G. Sabau, I. Lungu, R. Bologa, and A. R. Bologa, "Information Systems in University Learning," vol. 14, no. 4, pp. 171-182, 2010.

[23] T. Sahama and H. Pillay, "Realisation of University-Industry Collaboration Through Industry-Based Learning At Indonesian Higher Education,” no. March, pp. 3853-3863, 2016.

[24] L. L. Ellingson and D. Ph, "Communication, Collaboration, and Teamwork among Health Care Professionals," vol. 21, no. 3, 2002.

[25] Freeman, et al, "the impact of individual philosophies of team work on multi professional practice and the implications for education, 2000.

[26] L. A. Halawi, R. V. McCarthy and J. E. Aronson, "An empirical investigation of knowledge management systems". The Journal of Computer Information Systems, 2007, pp.121-136.

[27] S. Petter, W. DeLone, and E. McLean, "Measuring information systems success: models, dimensions, measures, and interrelationships," Eur. J. Inf. Syst., vol. 17, no. 3, pp. 236-263, 2008.

[28] V. Venkatesh and S. A. Brown, "Research essay bridging the qualitative - quantitative divide: guidelines for conducting mixed methods", pp. 1-34, 2013.

[29] J. W. Creswell, "Steps in Conducting a Scholarly Mixed Methods Study". DBER Speaker Series, pp. 54, 2013.

[30] L. W. T. Daniel, "Qualitative Interview Design: A Practical Guide for Novice Investigators Qualitative Interview Design: A Practical Guide for Novice Investigators", vol. 15, no. 3, pp. 754-760, 2010.

[31] P. Burnard, "A method of analysing interview transcripts in qualitative research”. Nurse Education Today, vol. 11, pp. 461-466, 1991. 